\title{
On the Advantages and Disadvantages of Internet Public Opinion
}

\author{
Xinhua $\mathbf{L i}^{1}$, Zichen $\mathbf{L i}^{2}$ \\ ${ }^{1}$ School of Literature and Journalism and Communication, Shandong University of Technology, Zibo, Shandong, China \\ ${ }^{2}$ Shandong University of Technology Library, Zibo, Shandong, China
}

\begin{abstract}
Internet public opinion is an influential and tendentious opinion or speech expressed by the public on the Internet to a certain focus, which has formed a powerful force of public opinion. Internet public opinion has become a concentrated reflection of public opinion, opening up another channel to truly reflect public opinion, and effectively promoting the supervision of government officials and their decisions. In view of the strong emotional weakness of the current network public opinion, we can train forum opinion leaders to guide the public opinion with affinity and consideration, and select and enlarge the network public opinion by connecting the traditional media.
\end{abstract}

Keywords: Internet public opinion, Network public opinion supervision, Popular will.

\section{Introduction}

As the fourth media, the network media has gradually gained its position in the increasingly fierce media competition, and its influence has penetrated into people's political, economic, cultural and other aspects comprehensively and profoundly, becoming an indispensable means and way of news communication activities. Because of the freedom, interactivity and openness of network communication, the freedom of personal expression and speech that could not be realized in traditional news media in the past has been displayed unprecedentedly. Anyone who has access to the Internet can say anything and speak freely, thus forming a "free market" of speech.

The Internet has become a new type of media, and online public opinion is the influential and tendentious opinions or remarks expressed by the public on the Internet to a certain focus. Network public opinion seems to have countless eyes, ears and lips, which surround people's thoughts and behaviors all the time.

\section{Analysis on the Characteristics of Network Public Opinion}

\subsection{Compared with Traditional Media, Network Public Opinion Has Obvious Advantages}

(1) The mass, specialization and rapidity of information; (2) The simultaneity, personalization and interaction of information dissemination; (3) The integration of sound, picture and text. But there are also some shortcomings: lack of rigor, profundity and authority. Therefore, network public opinion has the following main characteristics different from public opinion such as radio, newspapers and television:

\subsubsection{Internet Public Opinion Is Relatively Rich and Free}

The dissemination of information by traditional radio, newspapers, magazines, TV, movies and media should be controlled by certain countries, political parties or social organizations. The current law also clearly stipulates the corresponding ways of examination and control, so it is based on conscious public opinion. Internet public opinion is mainly spontaneous, although there are also conscious public opinions of political parties and social organizations on the Internet, which together form a vast world of public opinion.

\subsubsection{It Is More Difficult to Control Online Public Opinion Than Traditional Media}

It is not difficult to control the public opinion of traditional mass media. Governments of various countries regulate mass communication by stipulating the mass communication system, formulating relevant laws, regulations and policies, allocating communication resources, auditing and registering the establishment of new media, restricting or prohibiting the dissemination of certain information contents, etc. However, the Internet is a highly open space. Due to the need of resource sharing, many information exports are not approved by the press and publication department. It is quite easy to send emails anonymously and participate in BBS discussions on the Internet, and emails are easily intercepted, altered and forged. The openness of the network theoretically makes everyone a "news publisher". For a large number of Internet users, it is difficult to control the generation stage and dissemination of public opinion. It is impossible to check every speech on the "information highway", let alone make a comprehensive evaluation of it, which makes the control of network public opinion complex and difficult to operate. The uncontrollability of network public opinion is the most important characteristic of network public opinion, and other characteristics of network public opinion are derived from the uncontrollability.

\section{Network Public Opinion Has Become A Force of Public Opinion That Can Not Be Ignored}

In China, online public opinion is mainly reflected and formed by media comments, BBS and news posts in the network. In recent years, almost every major event at home and abroad has aroused strong response and heated debate in the online media, forming a "free market" of speech. In the Opinion Channel and Powerful Country Forum of People's Daily Online, Xinhua Speech and Development Forum of Xinhua.com, Insight into the World of International Online, 
Red Pepper Review of Red Net, Qianlong Review of Qianlong.com, Oriental Review of Dongfang.com, Youth Topic of China Youth Online, and news posts of Sina.com and Sohu.com. These constructive views and viewpoints in media speeches and forums (BBS) and news posts from various websites have even had an impact on the decision-making and governance of relevant departments.

The activity of netizens' speech has reached an unprecedented level. Whether it is a major domestic event or an international event, it can immediately form online public opinion, and even generate huge public opinion pressure, which can not be ignored by any department, institution or even public figures. In the past, only the powerful class and the intellectual elite had the right to speak, while the Internet enabled the general public, including vulnerable groups and marginal groups, to have a certain right to speak. At present, the constructive influence of online public opinion is embodied in the following aspects:

\subsection{Network Public Opinion Is A Concentrated Reflection of Public Opinion}

The intensiveness, universality and visibility reflected by public opinion get the most obvious response in online public opinion. The online public opinion is the most representative among the existing means that can reflect public opinion more truly, directly and timely. The messages of major websites fully express public opinion, and form the network public opinion with viewpoints and summaries. After the netizen's message is amplified into a point of view, the network media and print media will interact with each other, which will immediately promote the views and voices that are more representative of public opinion. With such interaction, a widely promoted public opinion appears, so it naturally begins to affect the government's decision-making. This process is roughly the same: interview and report of print media - reprint of online media - comments from netizens forming public opinion experience - conceptualized online public opinion - interaction between online media and print media - specific online public opinion (improving public opinion) - affecting government decision-making.

\subsection{Network Public Opinion Has Opened Up Another Channel to Truly Reflect Public Opinion}

Before 2003, ordinary people, when faced with the situation that could not be solved or claimed, first looked for the government at the next higher level or related institutions. The second step is to look for influential traditional media. However, the search for online media has not been deeply recognized before 2003, and this state has undergone a subversive change since 2003. Sensitive traditional media began to intervene in it, so the interaction between online media, traditional media and netizens' comments soon formed.

Internet public opinion is the most fruitful result of human civilization combining high technology and democracy. Network media is an all-weather information dissemination and real-time information release, which completely gives the time possession to the audience, and immediacy increases the impact of public events. Internet media breaks the monopoly of discourse privilege, and transfers some discourses to the audience. The audience can express their views timely, conveniently and fully by pasting, editing, linking and freely expressing their comments. They are both recipients and publishers of information. When information flows freely on the Internet and attracts many audiences to participate actively, the role of information "gatekeeper" will be greatly weakened or even completely eliminated. Even if it is "deleted", it can make its own protest. The information on the network media, especially the information generated by the high participation of the audience, has strong personalized characteristics, which shortens the emotional and psychological distance between the media and the audience. People call it the zero distance communication of information. Speaking online is like speaking at home.

\subsection{Network Public Opinion Will Supervise Decision-makers and Decision-making and Other Related Factors}

Why supervision? What is the basis or motivation of supervision?

First, people are flawed, animals still remain in people, and animals lurk in people's hearts, so people will be negligent, make mistakes and do evil, and supervision is one of the ways to prevent and stop them. The ancients put forward "cautious independence", which shows that people are easy to commit crimes when dealing with "independence", and the hidden black beast may jump out. Supervision is to put everyone in the sun, because it is open and can not be "alone", which will prevent and reduce the chances of committing crimes.

Second, people are social people. Everyone needs to adapt to their own living environment and abide by the social behavior rules. Therefore, the environment and rules can act as a deterrent to people's behavior, just as the so-called "people can be feared". Supervision is to maintain rules, purify the environment and give full play to their restrictive role.

Third, groups, organizations and power people have more energy than ordinary individuals. This energy may be benign or malignant. Without supervision, once out of control, it often leads to madness, autocracy and evil. This has been fully proved by social practice at all times and in all countries. Absolute power absolutely leads to corruption. In a modern society ruled by law, we can pray that everyone has sober rationality and shining divinity. But we can't pin our hopes on people's conscience discovery. Some good hopes often become an encouragement to evil.

So supervision is necessary, so who will supervise? Who is qualified to supervise? This is the subject of supervision.

Supervision must abide by a basic principle, that is, the separation of supervision subject and object, and never the integration of subject and object. Self-supervision has already become a modern farce. Now shouting "Keep your mouth shut, don't eat what you shouldn't eat; Hold your hand, don't take what you shouldn't take; Take care of your legs and don't go where you shouldn't go. " But why can't so many people control it? The reason is that your mouth, hands and eyes all grow on yourself. If they grow on others, it will be easy to manage. Therefore, under the principle of supervising the separation of subject and object, any group and any citizen have the power of supervision. In short, everyone is the subject of supervision, and everyone has the power of supervision, so that social relations can form a benign interaction of checks and balances.

Network supervision by public opinion means that people can learn about state affairs through the Internet, widely and fully communicate and express their opinions and suggestions, and praise and evaluate the national political, economic, legal, cultural, educational, administrative and other activities. The 
Internet has become the best means of public opinion expression. The relationship between supervision and being supervised has never been as obvious as network public opinion. After the formation of network public opinion, it will form a huge force on decision-makers and decision-makers, especially in some major events and decision-making related to the people. After the network public opinion forms a strong voice, the relevant departments will face up to this voice and hold a press conference to correct the audio-visual situation.

\section{Network Public Opinion Helps Decision Makers Understand the Trend of Public Opinion, Understand the Situation of the People and Obtain the Support of Low-level People}

Public opinion is the universal consciousness of the whole society. Public opinion is usually expressed in three forms: latent public opinion, explicit public opinion and behavioral public opinion. Latent public opinion is a low-level public opinion or a public opinion in the formative period, which is manifested by the people's consistent inner activities. At this time, public opinion is in a state of social emotion. If the latent public opinion is further upgraded, it will turn into explicit public opinion. At this time, the public opinion is expressed as a social consensus with a complete opinion form; If public opinion is expressed not only by words, but also by actions, it constitutes the behavioral public opinion of public opinion. Online public opinion is mostly in the form of latent public opinion, which is a kind of emotional catharsis and typical emotional online public opinion.

Throughout history, before this, Chinese people have never been able to obtain information and express their wishes and demands quickly and conveniently through an interactive communication tool like today, and policy makers have never been able to keep close contact with the people at the bottom with a modern tool like today. This technological change may have a far-reaching historical impact, especially it may help decision makers at different levels to directly obtain the support of the bottom people. From the comments of netizens, decision makers can feel the trend of public opinion, see the back of the people and the likes and dislikes of the people, so it is possible to make more popular and reasonable decisions, which is very necessary.

\section{References}

[1] Liu Linxiao. On the development trend and social influence of Internet public opinion. Legal System and Society, 2013.1.

[2] Wu Ting. Talking about the social influence of online public opinion. News Communication, 2017.4.

[3] Yang Fan. The Negative Influence of Internet Public Opinion and Its Guiding Strategies. News Research Guide, 2019.16.

[4] Wang Jipeng. Analysis and Interpretation of Internet Public Opinion. Blog China on May 30, 2005.

[5] Xie Yishu. Thoughts on the status quo of Internet public opinion in the era of new media. News Research Guide, 2018.20 .

[6] Tong Shuai. Analysis of Internet public opinion in the selfmedia era. News World, June 2013.

[7] Xian Yan. Internet public opinion is another chess piece of the government on May 1, 2005.

[8] Wei Hong. The double-sided influence of Internet public opinion and regulatory guidance. Public Administration 2009.6.

[9] Shen Liuhong. The formation and three-dimensional guidance of Internet public opinion. Jingchu.com.cn, May 30, 2005.

[10] Li Biao. Analyze the "negative preferences" of Internet public opinion from these five points. Beijing Daily, 2021.9.16. 